\title{
Identification of Rifampin-inducible P450IIIA4 (CYP3A4) in Human Small Bowel Enterocytes
}

\author{
Joseph C. Kolars, * Phyllissa Schmiedlin-Ren, * John D. Schuetz, * Che Fang, * and Paul B. Watkins * \\ *Departments of Internal Medicine, University of Michigan Medical Center, and the Veterans Administration Medical Center, Ann \\ Arbor, Michigan 48109; and ${ }^{\ddagger}$ Department of Internal Medicine, Medical College of Virginia, Richmond, Virginia 23229
}

\begin{abstract}
Enzymes within the P450IIIA (CYP3A) subfamily appear to account for significant "first pass" metabolism of some drugs in the intestine. To identify which of the known P450IIIA genes are expressed in intestine, enterocyte RNA was hybridized on Northern blots with synthetic oligonucleotides complementary to hypervariable regions of hepatic P450IIIA4, P450IIIA5, and P450IIIA7 cDNAs. Hybridization was detected only with the P450IIIA4-specific oligonucleotide. The identity of the hybridizing mRNA was confirmed to be P450IIIA4 by direct sequencing of a DNA fragment amplified from enterocyte cDNA by the polymerase chain reaction. To determine if enterocyte P450IIIA4 is inducible, biopsies of small bowel mucosa were obtained from five volunteers before and after they received $7 \mathrm{~d}$ of treatment with rifampin, a known inducer of P450IIIA4 in liver. Rifampin treatment resulted in a five- or eightfold mean increase $(P<0.05)$ in the biopsy concentration of P450IIIA4 mRNA when normalized for content of sucrase isomaltase or intestinal fatty acid binding protein mRNAs, respectively. Rifampin also induced P450IIIA immunoreactive protein in enterocytes in each of the subjects, as judged by immunohistochemistry, and resulted in a 10-fold increase in P450IIIA4-specific catalytic activity (erythromycin $N$-demethylation) in the one patient studied. Our identification of inducible P450IIIA4 in enterocytes may in part account for drug interactions characteristic of P450IIA4 substrates and suggests a strategy for controlling entry into the body of a major class of xenobiotics. (J. Clin. Invest. 1992. 90:1871-1878.) Key words: cytochrome P450 • enterocyte - gastrointestinal tract $\bullet$ P450IIIA - cyclosporine A $\bullet$ immunohistochemistry
\end{abstract}

\section{Introduction}

Enzymes within the P450IIIA subfamily account for up to $25 \%$ of the total cytochrome P450 found in liver (1). There has been considerable interest in these enzymes because they have been recently shown to metabolize dietary mycotoxins such as aflatoxin B1 (2) and many commonly used medications. The list of drugs known to be metabolized by P450IIIA enzymes is rapidly expanding and currently includes cyclosporine A (3, $4)$, nifedipine $(5,6)$, erythromycin (1), lidocaine (7), quinidine (8), midazolam, triazolam (9), lovastatin (10), and tamoxifen (11).

Address correspondence and reprint requests to Paul B. Watkins, M.D., University of Michigan Medical Center, 7A119-UH, 1500 East Medical Center Drive, Ann Arbor, MI 48109-0108.

Received for publication 4 March 1992 and in revised form 15 May 1992.

The Journal of Clinical Investigation, Inc.

Volume 90, November 1992, 1871-1878
Four distinct P450IIIA proteins have been identified in human liver (P450IIIA3, P450IIIA4, P450IIIA5, and P450IIIA7) and it appears that each reflects expression of a unique gene (12). (In this manuscript, the terms P450IIIA3, P450IIIA4, P450IIIA5, and P450IIIA7 correspond to the recently proposed terms CYP3A3, CYP3A4, CYP3A5, and CYP3A7, respectively [12]). It seems unlikely that many additional P450IIIA genes exist because a single P450IIIA gene is $\sim 30 \mathrm{~kb}$ in length (Schuetz, J., unpublished observations) and only 90 $\mathrm{kb}$ of human genomic DNA hybridize with a P450IIIA cDNA under low stringency (13). The four known P450IIIA enzymes share $>84 \%$ amino acid sequence identity (12). In spite of this high structural similarity, there are significant differences between some of these enzymes in terms of catalytic properties $(14,15)$. There also appear to be differences in the regulation of these enzymes. For example, the major P450IIIA gene expressed in adult human livers appears to be P450IIIA4 (16). The liver content and catalytic activity of P450IIIA4 is increased (induced) when patients are treated with a variety of compounds $(17,18)$, including the commonly used antibiotic rifampin (19-21). In contrast, P450IIIA5 has been detected in only $10-30 \%$ of adult human livers (22), and there is no evidence that the enzyme is inducible (22).

Characterization of the P450IIIA enzymes in liver has provided potential explanations for drug interactions involving cyclosporine A (CsA). ${ }^{1}$ CsA has been shown to be metabolized by P450IIIA4 in the liver $(3,4,14)$. Drugs that inhibit P450IIIA4 activity in liver, such as erythromycin or ketoconazole (20), can significantly elevate CsA blood levels in patients $(23,24)$. Conversely, many drugs that induce P450IIIA4 in liver, such as rifampin, can decrease CsA blood levels in patients (25). This has suggested that drug interactions involving CsA are caused by alterations in P450IIIA4 activity in the liver $(3,20,26)$.

We have recently shown that orally administered CsA undergoes significant "first pass" metabolism in the intestine (27). When CsA was instilled into the small bowel of the two patients during the anhepatic phase of the liver transplant operation, hydroxylated and $N$-demethylated metabolites of CsA were readily detected in the portal blood. In one patient, metabolites accounted for $\sim 50 \%$ of the drug that had been absorbed into the portal blood. Based on this data, we concluded that the contribution of the intestine to CsA metabolism might rival or actually exceed that of the liver (27).

It seems likely that metabolism of CsA that occurs within the intestine is catalyzed by enzymes within the P450IIIA fam-

1. Abbreviations used in this paper: CsA, cyclosporine A; EGD, esophagogastroduodenoscopy; FABP, intestinal fatty acid binding protein; GT, guanadinium isothiocyanate; KP, potassium phosphate; MOPS, 3-(4-morpholino) propane sulfonic acid; PCR, polymerase chain reaction; SI, sucrase-isomaltase. 
ily for several reasons. First, the metabolites we identified in portal blood (27) are those characteristically produced by P450IIIA enzymes in liver $(3,4,14)$. In addition, we have recently shown that intestinal first pass metabolism of CsA is catalyzed by P450IIIA enzymes within small bowel epithelial cells (enterocytes) in an in vivo rat model (28). Finally, human enterocytes also appear to contain enzymes within the P450IIIA subfamily. This is because a monoclonal antibody that recognizes all of the known P450IIIA proteins reacts on immunoblots with a human enterocyte protein (29). In addition, a P450IIIA3 cDNA hybridizes to enterocyte RNA on Northern blots under low stringency (29). In aggregate, these observations indicate that enterocyte enzymes within the P450IIIA family probably account for significant "first pass" metabolism of CsA in patients. However, because it has not been established which, if any, of the known P450IIIA genes are expressed or are inducible in enterocytes, it is unknown whether drug interactions characteristic of P450IIIA substrates could be occurring at the level of the intestine. In this report, we show that P450IIIA4 is present and inducible in human enterocytes.

\section{Methods}

Patient samples and treatments. Human tissue was obtained from surgically resected proximal small bowel (jejunum), hepatoma, liver (adult and fetal), kidney (adult and fetal), lung, and placenta, and frozen in $4 \mathrm{M}$ guanadinium isothiocyanate (GT) for later RNA extraction. Enterocytes were isolated from proximal jejunum by calcium chelation as previously described (29) before freezing in $4 \mathrm{M} \mathrm{GT}$.

Five volunteer adults underwent esophagogastroduodenoscopy (EGD) (after an overnight fast) both before and immediately after receiving rifampin $300 \mathrm{mg}$ twice daily orally for $7 \mathrm{~d}$. During each endoscopy, six "pinch biopsies" of small bowel mucosa (second portion of the duodenum) were obtained and immediately placed in formalin ( 2 biopsies) or 4 M GT solution (four biopsies) for processing as described below. The subjects received no medications (other than rifampin) during the study. Subject A is a 28 -yr-old black female, B is a 25-yr-old white male, $\mathrm{C}$ is a 34 -yr-old white female, $\mathrm{D}$ is a 21 -yr-old white male, and E is a 35 -yr-old white male. Subject $\mathrm{E}$ had been biopsied 6 mo before the start of the study. He also underwent additional endoscopic biopsies $24 \mathrm{~h}$ after starting the 7-d rifampin treatment and again $3 \mathrm{~d}$ after his last dose of this medication. At a later date, he underwent EGD with small bowel biopsies before and immediately after receiving oral rifampin $\mathbf{3 0 0} \mathrm{mg}$ twice daily for $\mathbf{2 d}$. These biopsies were processed for enzymatic studies as outlined below. All studies were approved by the Human Studies review board of the University of Michigan Medical School.

$R N A$ extraction. The method of Chomczynski (30) was used to isolate total RNA from the various human tissues. Endoscopically obtained specimens were treated as follows: Four biopsy specimens were placed in $1.2 \mathrm{ml}$ of $4 \mathrm{M} \mathrm{GT} / 0.5 \% \mathrm{~N}$-lauroylsarcosine $/ 25 \mathrm{mM}$ sodium citrate ( $\mathrm{pH}$ 7.0)/0.7\% 2-mercaptoethanol, homogenized with a handheld dounce, stored at $-80^{\circ} \mathrm{C}$, and later processed according to the published protocol. RNA was quantified by determining ultraviolet light (UV) absorption at $260 \mathrm{~nm}$ of a suspension in water.

Northern blot hybridization and analysis. Total RNA $(30 \mu \mathrm{g})$ was subjected to electrophoresis in $1.0 \%$ agarose gels with $5 \times 3-(4$ morpholino) propane sulfonic acid (MOPS) buffer containing $2.2 \mathrm{M}$ formaldehyde in $1 \times$ MOPS buffer for $4 \mathrm{~h}$ at $80 \mathrm{~V}$. The ethidium staining of the resolved ribosomal RNA bands confirmed that little degradation of RNA had occurred in each tissue. The RNA was then transferred by capillary action using $20 \times$ standard saline citrate onto nylon and crosslinked by ultraviolet (UV) irradiation of $1,200 \mathrm{~J}$. This membrane was initially hybridized with a cDNA for human sucrase-isomaltase (31), a generous gift from Dr. Peter Traber, labeled with ${ }^{32} \mathrm{P}$ by a random priming reaction. After washing, autoradiography, and stripping of the cDNA, this same blot was subsequently hybridized with the following antisense synthetic oligonucleotides that had been end-labeled with ${ }^{32} \mathbf{P}$ using T4 kinase. The P450IIIA oligomers were chosen to be complementary to hypervariable regions of the P450IIIA cDNAs. They are identified below by the numbered basepairs of the published sequence: P450IIIA4 cDNA (5), bp 1727-1757 (5' AGC TCA ATG CAT GTA CAG AAT CCC CGG TTA 3'); P450IIIA5 cDNA (14), bp 1619-1646 (5' GGG GCA CAG CTT TCT TGA AGA CCA 3'); P450IIIA7 cDNA (32), bp 1708-1738 (5' CTT CCC CAG CAC TGA TTT GGT CAT CTC CTC $3^{\prime}$ ); intestinal fatty acid binding protein gene (3.3), bp 25392569 ( 5' AGT ATT CAG TTC GTT TCC ATT GTC TGT CCG 3').

The integrated optical density of each hybridization band was measured from each autoradiogram with a Zeiss computer assisted video densitometer (Eastern Microscope Co., Raleigh, NC).

PCR analysis and nucleotide sequence analysis. Total RNA from human duodenum was reverse transcribed to cDNA by incubating $1 \mu \mathrm{g}$ of RNA with $3 \mu \mathrm{g}$ of oligo-dT ( Pharmacia Fine Chemicals, Piscataway, $\mathrm{NJ}$ ), $1 \mu \mathrm{l} 25 \mathrm{mM}$ dNTP, $5 \mu \mathrm{l}$ buffer ( $500 \mathrm{mM}$ Tris pH 8.3, $500 \mathrm{mM}$ $\mathrm{KCl}, 80 \mathrm{mM} \mathrm{MgCl}, 100 \mathrm{mM}$ DTT) and $1 \mu \mathrm{l}$ reverse transcriptase (Seikagaku America, Inc., Rockville, MD) in a reaction volume of 50 $\mu \mathrm{l}$ for $1 \mathrm{~h}$ at $41^{\circ} \mathrm{C} .10 \mu \mathrm{l}$ of this reaction mixture was then added to $5 \mu \mathrm{l}$ of $1 \mathrm{mM} \mathrm{dNTP}, 5 \mu \mathrm{l} \mathrm{Taq}$ buffer $(400 \mathrm{mM} \mathrm{KCl}, 0.1 \%$ gelatin $), 3.5 \mathrm{U}$ Taq polymerase (Perkin-Elmer Cetus Instruments, Norwalk, CT), and $1 \mu \mathrm{g}$ of a sense primer common to all four P450IIIA cDNAs (bp 13751402 [5], 5' CCT TAC ACA TAC ACA CCC TTT GGA AGT 3') and the P450IIIA4 specific antisense primer (as listed above for Northern blot hybridization) in a final reaction vol of $50 \mu l$. These primers span an intron in the P450IIIA4 gene (Schuetz, J., unpublished observations) and should amplify a 382-bp segment of the P450IIIA4 cDNA. Samples were subjected to 19 cycles of the polymerase chain reaction (PCR) with a DNA thermal cycler (Perkin-Elmer Cetus Instruments) and stringent conditions ( 45 -s denaturation step $\left[94^{\circ} \mathrm{C}\right]$, extension for $75 \mathrm{~s}\left[65^{\circ} \mathrm{C}\right]$ and no annealing step). A final $65^{\circ} \mathrm{C}$ extension step was performed for $10 \mathrm{~min}$ at the end of the 19 cycles. $20 \mu \mathrm{l}$ samples were subjected to electrophoresis (along with a sample containing standardized DNA fragments of known size) at $65 \mathrm{~V}$ on a $1 \%$ agarose $/ 2 \%$ NuSieve (FMC Bioproducts, Rockland, ME) $1 \times(0.04 \mathrm{M}$ Tris acetate, $0.001 \mathrm{M}$ EDTA, pH 8.0 [TAE]) gel containing ethidium bromide ( 2 $\mu \mathrm{M})$. The amplified DNA fragment was visualized and sized relative to the standards under UV light.

The DNA fragment was purified by agarose electrophoresis. The ends of the PCR product were filled in with the Klenow fragment of DNA PolI and the blunt-ended product was subcloned in both orientations into M13 phage at the Smal site. Single-stranded M13 was prepared from several different plaque-purified recombinants to determine the nucleotide sequence of the cloned insert using the method of Sanger et al. (34). Results were confirmed by sequencing each region of the cDNA at least three times. Global alignments of published sequences were made with the Genetics Computer Group (Madison, WI) GAP Program.

Immunohistochemistry. Formalin-fixed biopsies from the small bowel were subjected to immunoperoxidase staining (Zymed Streptavidin-Biotin System Histostain Kit; Zymed Laboratories, South San Francisco, CA). In brief, formalin-fixed tissues were embedded, sectioned, and deparafinized. The slides were incubated with $10 \%$ nonimmune serum for $10 \mathrm{~min}$ followed by a 35-min incubation with varying dilutions of the primary antibody raised in a rabbit to purified P450IIIA3/4 (a generous gift from Dr. Steve Wrighton, Eli Lilly and Co., Indianapolis, IN). This antibody has been shown to react with all known human P450IIIA proteins (15). This antibody does not react on immunoblots with purified proteins in the P450I (CYPI) or P450II (CYP2) families ([15], Dr. Steve Wrighton, unpublished observations). The tissue section was then sequentially incubated with a biotinylated second antibody, streptavidin-peroxidase conjugate, and finally the chromogen aminoethyl carbazole with $0.03 \%$ hydrogen peroxide. Thorough washing was performed after each incubation, and the 
tissue was counterstained with hematoxylin. Immunoreactive protein was identified as red staining (appearing black on the photomicrographs). This staining was completely inhibited when the antibody was preincubated with purified P450IIIA3/4.

Stained slides were judged by William O. Dobbins III, M.D., in a blinded fashion for relative amounts of immunoreactive protein. Staining intensity was graded on a $1-4+$ scale based on the intensity of staining in individual enterocytes as well as the total number of enterocytes that stained.

Enzymatic activity. Six small bowel biopsies were obtained from subject $E$ before and after he received rifampin $300 \mathrm{mg}$ twice daily for 2 d. The biopsies were immediately homogenized using a hand-held

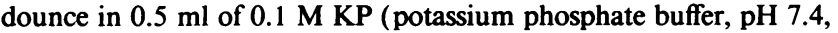
containing $0.23 \mathrm{mM}$ PMSF) and frozen at $-80^{\circ} \mathrm{C}$. At a later date, the homogenates were thawed and a portion of each was used to assay sucrase-isomaltase activity by the technique of Dahlqvist (35). The remaining homogenate was centrifuged at $9,000 \mathrm{~g}$ for $15 \mathrm{~min}$ and the supernatant was assayed for erythromycin demethylase activity by two different techniques. First, the Nash method (36) was used to quantitate the production of formaldehyde from the sample diluted to $1 \mathrm{mg}$ protein $/ \mathrm{ml}$ in $0.1 \mathrm{M} \mathrm{KP}$ buffer $\left(37^{\circ} \mathrm{C}\right)$ in a reaction mixture containing $0.4 \mathrm{mM}$ erythromycin and $1.0 \mathrm{mM}$ NADPH. This was performed as previously described (37), except that the incubation volume was reduced to $100 \mu \mathrm{l}$. A second radiometric assay was also used to quantitate erythromycin demethylase activity in the samples. This assay is similar to that described by Nebert and Poland for detecting production of $\left[{ }^{14} \mathrm{C}\right]$ formaldehyde from $\left[{ }^{14} \mathrm{C}\right] \mathrm{N}$-methyl aminopyrine (38), and relies on the fact that erythromycin is highly lipophilic and can therefore can be separated from formaldehyde in an organic/aqueous phase extraction. $250 \mu \mathrm{l}$ of the biopsy supernatant was diluted to $0.2 \mathrm{mg}$ protein $/ \mathrm{ml}$ in $0.1 \mathrm{M} \mathrm{KP}$ buffer and was incubated $\left(37^{\circ} \mathrm{C}\right.$ for $\left.15 \mathrm{~min}\right)$ with $300 \mathrm{nmol}$ NADPH and $125 \mathrm{nmol}$ erythromycin containing 3.1 $\mathrm{nmol}\left[{ }^{14} \mathrm{C}\right] N$-methyl] erythromycin (New England Nuclear, Boston, MA) at a final sp act of $1.35 \mathrm{mCi} / \mathrm{mmol}$. Water soluble impurities were removed from the $\left[{ }^{14} \mathrm{C}-\mathrm{N}\right.$-methyl] erythromycin before the assay by performing a single chloroform extraction and drying the chloroform under nitrogen. The reaction was terminated by the addition of $4 \mathrm{ml}$ of chloroform $\left(4^{\circ} \mathrm{C}\right)$ and $1.5 \mathrm{ml}$ of $0.1 \mathrm{~N} \mathrm{NaOH}$. After vortexing and centrifugation at $1,000 \mathrm{~g}$ for $5 \mathrm{~min}$ at $27^{\circ} \mathrm{C}$, the extraction was repeated by adding $1.0 \mathrm{ml}$ of the aqueous supernatant to $4 \mathrm{ml}$ of chloroform and $0.5 \mathrm{ml}$ of $0.1 \mathrm{~N} \mathrm{NaOH}$. The resulting supernatant $(0.5 \mathrm{ml})$ was added to $10 \mathrm{ml}$ of Aquasol-2 liquid scintillation cocktail (New England $\mathrm{Nu}$ clear) and subjected to scintillation counting. The quantity of formaldehyde formed was calculated as described by Poland and Nebert (38), and control incubations were performed by omitting the NADPH. Each sample was assayed in duplicate.

\section{Results}

Identification of P450IIIA4 in enterocytes. To determine which of the four known P450IIIA genes were expressed in human enterocytes, oligonucleotides were synthesized to hypervariable regions of P450IIIA4, P450IIIA5, and P450IIIA7 mRNAs. P450IIIA3 mRNA shares $>98 \%$ nucleotide basepair identity with P450IIIA4 mRNA, preventing the design of an oligonucleotide that would selectively hybridize with P450IIIA3, but not with P450IIIA4 mRNA $(13,16,39)$. However, nucleotide sequence alignment of P450IIIA3 and P450IIIA4 cDNAs reveals that P450IIIA4 contains a 20-bp insert in its $3^{\prime}$ untranslated region (16). This allowed us to synthesize a P450IIIA4 specific 30 -mer oligonucleotide that shared only 9,8 , and 26 , bp in this same region when aligned with P450IIIA3, P450IIIA5, and P450IIIA7, respectively.

RNA prepared from human enterocytes was hybridized on a Northern blot with each of the radiolabeled oligonucleotides. RNA prepared from other human tissues was also analyzed on the same blot. Under high stringency, the P450IIIA4 specific oligonucleotide hybridized with the enterocyte RNA (Fig. 1) revealing two bands, corresponding to $2.2-$ and $3.0-\mathrm{kb}$ fragments of RNA. RNA prepared from fetal liver hybridized with the P450IIIA5 and P450IIIA7 specific oligonucleotides, consistent with prior observations that P450IIIA5 and P450IIIA7 are expressed in the fetus $(40,41)$. However, no hybridization was detected between the enterocyte RNA and either of these oligonucleotides.

To confirm that the P450IIIA4 oligonucleotide was hybridizing with P450IIIA4 mRNA, enterocyte mRNA was reverse transcribed to cDNA and amplified under stringent conditions by the polymerase chain reaction. The "antisense" P450IIIA4-specific oligonucleotide that was used to probe the Northern blot (Fig. 1) and a "sense" oligonucleotide complementary to all four known P450IIIA mRNAs (see Methods) were used as primers in the amplification. The amplified fragment was $382 \mathrm{bp}$ in length, exactly that predicted from the known nucleotide sequence of P450IIIA4 cDNA. This frag-
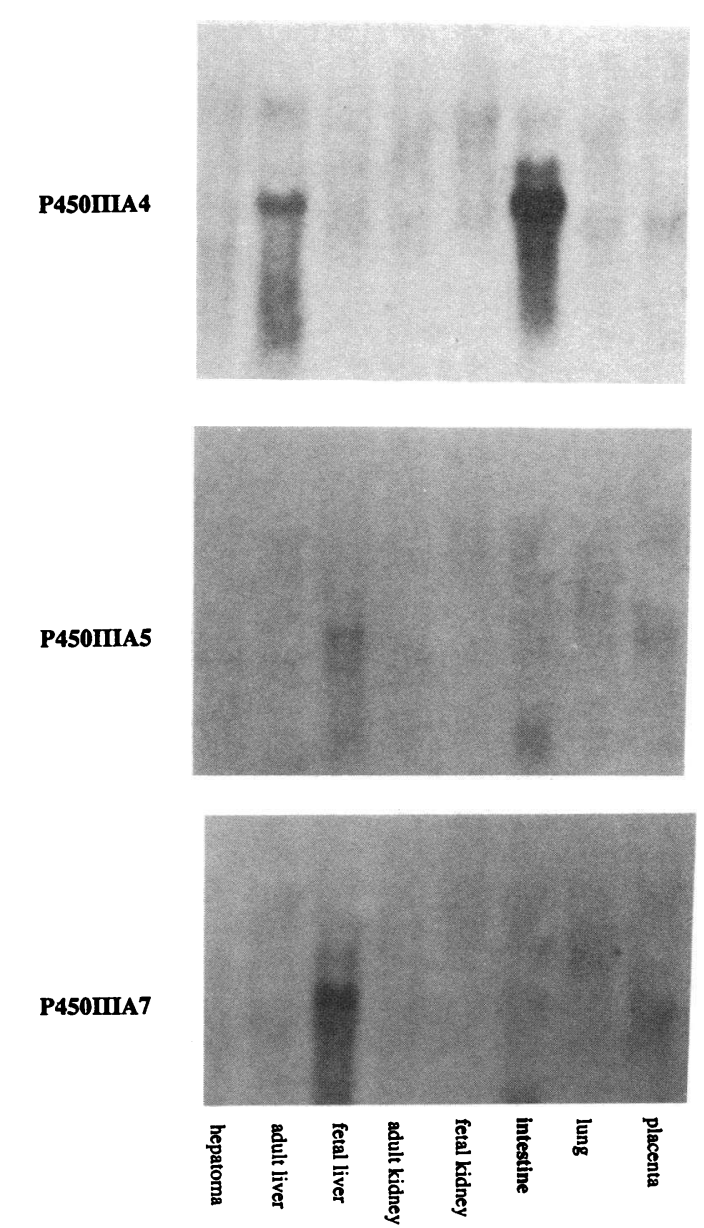

Figure 1. Identification of P450IIIA4 mRNA but not P450IIIA5 or P450IIIA7 mRNAs from human enterocytes. $30 \mu \mathrm{g}$ of total RNA isolated from enterocytes or from the indicated human tissues was subjected to agarose gel electrophoresis, transferred to nylon membrane, and hybridized with a ${ }^{32} \mathrm{P}$-end-labeled oligonucleotide complementary to a hypervariable region of P450IIIA4 mRNA under stringent conditions (see Methods). After visualization by autoradiography, the blot was stripped and rehybridized with a synthetic oligonucleotide probe specific for P450IIIA5 or then P450IIIA7. 
ment was then subcloned and sequenced as described in Methods. The derived nucleotide sequence of the fragment (between the primers) was $100 \%$ identical to the corresponding region of P450IIIA4, but was not identical to the corresponding regions of P450IIIA3, P450IIIA5, and P450IIIA7 (13, 45, and 24 bp mismatches, respectively).

Effect of rifampin treatment on enterocyte P450IIIA4. Rifampin is a known inducer of P450IIIA4 in liver. To determine if this medication also induces P450IIIA4 in enterocytes, we performed EGD in five healthy volunteers both before and after they were treated with oral rifampin ( $300 \mathrm{mg}$ twice daily) for $7 \mathrm{~d}$. At the time of EGD, six pinch biopsies of mucosa were obtained from the proximal small bowel (the second portion of the duodenum). Each biopsy weighed $\sim 5 \mathrm{mg}$. Total RNA was prepared from four of the six biopsies, and the remaining two biopsies were fixed in formalin, paraffin embedded, and sectioned. The tissue sections were then reacted with varying dilutions of a polyclonal antibody raised to P450IIIA3/4, as described in Methods.

P450IIIA immunoreactivity was detected only in mature enterocytes and not in crypt cells or in the many other cell types present in the biopsies. This was true in both the initial biopsies and in the biopsies obtained after treatment with rifampin (Fig. $2, A$ and $B)$. A dilution of primary antibody (1:750) that maximized the appearance of induction of immunoreactive protein was used in the sections shown in Fig. 2; when more concen- trated solutions of antibody were used, staining of P450IIIA protein in mature enterocytes was evident in the biopsies obtained before induction (not shown).

The stained sections from all five patients were submitted to an observer blinded to the timing of the biopsies relative to rifampin treatment (see Methods). In each patient, rifampin treatment was judged to have increased P450IIIA immunoreactive protein. Rifampin treatment was associated with both an increase in the intensity of enterocyte staining, as well as an increase in the total number of enterocytes stained (Fig. 2).

To determine if the induction in P450IIIA immunoreactive protein was associated with an increase in P450IIIA4 mRNA concentration, RNA isolated from the small bowel biopsies was hybridized on Northern blots with the P450IIIA4-specific oligonucleotide. As shown in Fig. 3, the intensity of hybridization to the small bowel RNA was greater after treatment with rifampin in each of the five subjects. The same blot was then stripped of the P450IIIA4 probe and rehybridized with probes for two other enterocyte specific mRNAs: intestinal fatty acid binding protein (FABP) and sucrase-isomaltase (SI). Despite comparable amounts of total RNA on the blot, as shown by ethidium bromide staining of ribosomal bands, the intensity of hybridization with the FABP or SI probes differed between biopsies (Fig. 3). This suggests that the proportion of intact enterocyte mRNA relative to total biopsy RNA varied between samples. However, rifampin treatment had no consistent effect
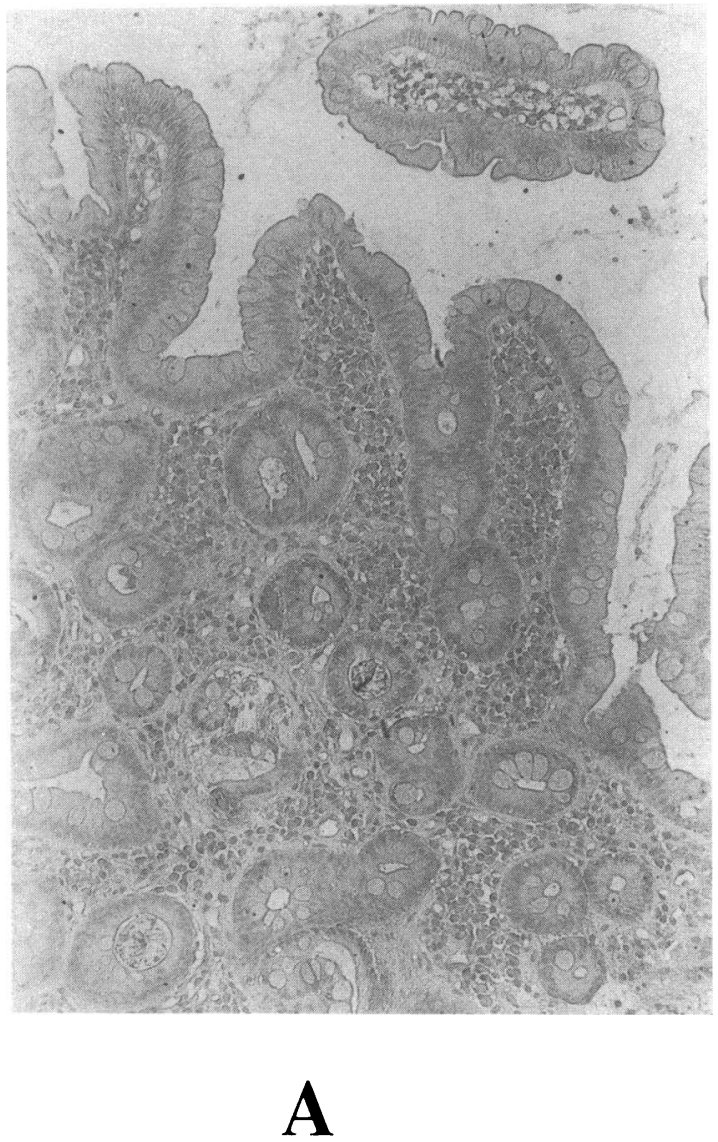

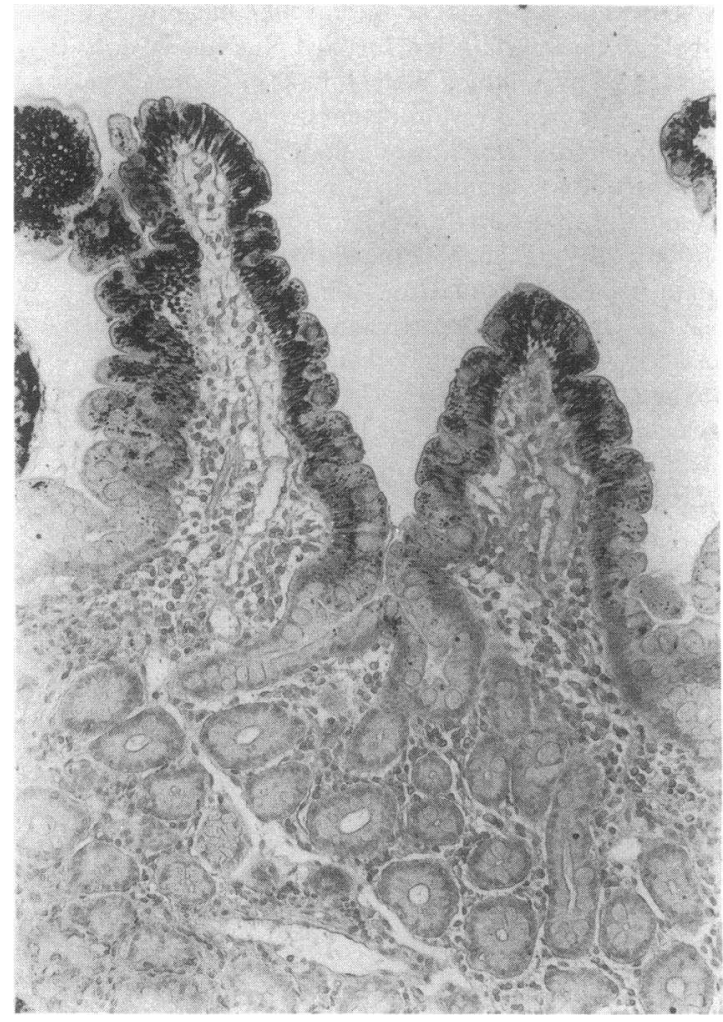

B

Figure 2. Induction of P450IIIA immunoreactive protein in biopsies obtained from subject $\mathrm{E}$ before $(A)$ and immediately after $(B)$ he received treatment with rifampin for $7 \mathrm{~d}$. Tissue was fixed in formalin, paraffin embedded and subjected to immunoperoxidase staining after incubation with anti-P450IIIA3/4 IgG (1:750) (see Methods). The black staining in mature enterocytes (best seen in $B$ ) indicates reactivity with the antibody. 



Figure 3. Northern blot hybridization of total RNA ( $30 \mu \mathrm{g})$ prepared from small bowel biopsies obtained in five volunteers before (con) and after ( $r i f$ a 7-d course of rifampin. After electrophoresis on agarose gels, the RNA was visualized by ethidium staining (top panel) and transferred to a nylon membrane. The blot was then sequentially hybridized with probes specific for P450IIIA4 mRNA, FABP mRNA, and SI mRNA.

on the apparent concentration of either the FABP or SI mRNAs.

Relative quantitation of the intensity of hybridization with each probe was determined by densitometry and expressed in arbitrary OD units. When all RNA samples shown in Fig. 3 were considered, there was a significant correlation between the hybridization with the FABP and SI probes $(r=0.7$, data not shown). To adjust for variation in enterocyte mRNA concentration, the P450IIIA4 hybridization signal OD was divided by that of FABP or SI. The mean induction of P450IIIA4 was approximately eightfold relative to FABP mRNA and fivefold relative to SI mRNA ( $P<0.05$ for each comparison, one-tailed paired $t$ test) (Fig. 4).

We also noted that before treatment with rifampin, the enterocyte concentration of P450IIIA4 mRNA in the five subjects appeared to vary $\sim 10$-fold, whether adjusted for FABP (0.23-2.87) or SI mRNA (0.55-6.18).

The blot shown in Fig. 3 was also hybridized with the P450IIIA5 and P450IIIA7 specific oligonucleotides. No hybridization was observed between any of the RNA samples and either probe (not shown).

Subject $\mathrm{E}$ had undergone small bowel biopsy 6 mo before the start of this study. He also underwent EGD and biopsy $24 \mathrm{~h}$ after receiving his first oral dose of rifampin (600 $\mathrm{mg}$ total), and $3 \mathrm{~d}$ after completion of the 7-d treatment. Total RNA prepared from each of these biopsies was hybridized on Northern blots with the P450IIIA4 specific oligonucleotide. There appeared to have been little change in the biopsy concentration
A



B

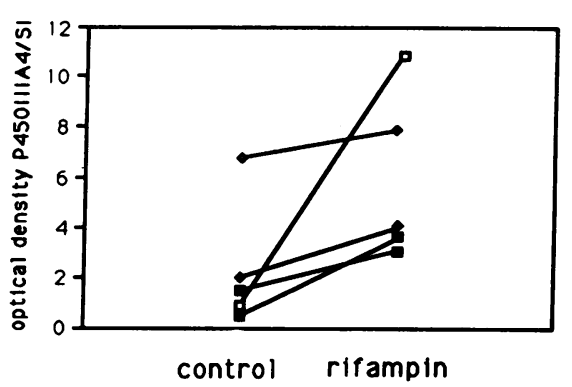

Figure 4. Induction of P450IIIA4 mRNA relative to two enterocyte specific mRNA's in the five volunteers receiving rifampin treatment for $7 \mathrm{~d}$. The Northern blot autoradiograms shown in Fig. 3 were analyzed by densitometry and the arbitrary OD units for P450IIIA4 hybridization was "corrected" for that observed with the FABP and SI probes.

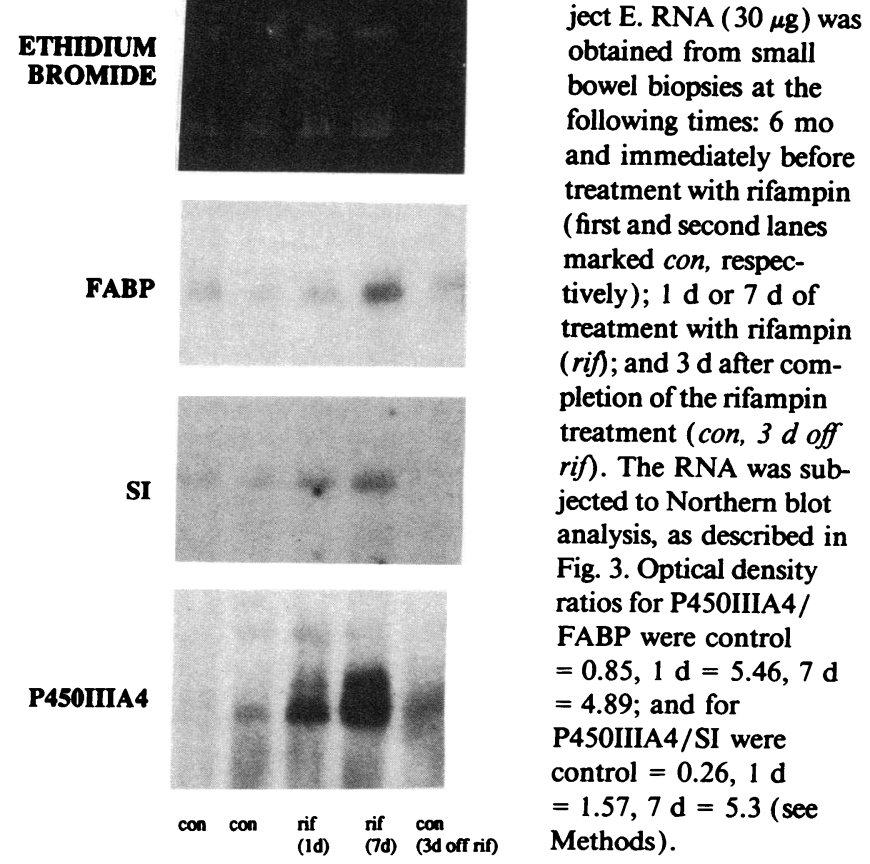

Figure 5. Time course of induction of enterocyte P450IIIA4 in subject E. RNA ( $30 \mu \mathrm{g})$ was obtained from small bowel biopsies at the following times: 6 mo and immediately before treatment with rifampin (frst and second lanes (rif); and $3 \mathrm{~d}$ after completion of the rifampin treatment (con, $3 d$ off rif). The RNA was subjected to Northern blot ratios for P450IIIA4/ control $=0.26,1 \mathrm{~d}$ Methods).
ABP were control 
of P450IIIA4 mRNA between the initial study EGD and the EGD performed 6 mo earlier (Fig. 5, second and first lanes marked "con," respectively). Induction of P450IIIA4 mRNA was evident within $24 \mathrm{~h}$ of receiving the first dose, increased further by $7 \mathrm{~d}$ of treatment, and returned to baseline levels within $72 \mathrm{~h}$ of the last rifampin dose. In contrast there appeared to be relatively little change in the concentration of FABP and SI mRNA in the biopsies (Fig. 5).

Finally, to determine if the rifampin mediated induction of P450IIIA 4 mRA and immunoreactive protein was associated with an increase in P450IIIA4 catalytic activity, we repeated EGD in subject $E$ both before and immediately after he received $2 \mathrm{~d}$ of treatment with rifampin ( $300 \mathrm{mg}$ twice daily). Homogenates were prepared from the biopsies and assayed for sucrase-isomaltase activity. The activity of this enterocyte specific enzyme was essentially unchanged by the rifampin treatment (pre-21 U/g vs. post-22 U/g). In contrast, erythromycin $N$-demethylase activity was induced $\sim 10$-fold by rifampin as measured by either a sensitive radiometric technique (pre$0.10 \mathrm{nmol} / \mathrm{mg}$ per min; post- $1.12 \mathrm{nmol} / \mathrm{mg}$ per $\min$ ) or by the conventional Nash colorimetric technique (pre- $0.13 \mathrm{nmol} / \mathrm{mg}$ per min; post-1.2 nmol/mg per min).

\section{Discussion}

We have provided evidence that P450IIIA4 is present in human enterocytes. An oligonucleotide complimentary to P450IIIA4 mRNA readily hybridized with RNA prepared from enterocytes, but oligonucleotides complimentary to P450IIIA5 and P450IIIA7 mRNAs did not (Fig. 1). The estimated sizes of the two species of RNA that hybridized to the P450IIIA4 specific probe (2.2 and $3.0 \mathrm{~kb}$, Figs. 1, 3, and 5) are consistent with the two known P450IIIA4 mRNAs present in liver; these are believed to result from alternate polyadenylation signals in the P450IIIA4 gene (16). The identity of the hybridizing mRNAs was further confirmed to be P450IIIA4 gene products by amplifying the enterocyte cDNA using the polymerase chain reaction and a P450IIIA4-specific oligonucleotide as one of the primers. The resulting DNA fragment had the exact length and nucleotide sequence predicted.

It is also clear from our data that P450IIIA4 mRNA is abundant in enterocytes. Indeed, the concentration of P450IIIA4 mRNA actually appeared to be greater in enterocytes than in liver (Fig. 1). It should be noted that our comparison to a single liver sample may not be representative in view of the large interpatient heterogeneity in the liver content of P450IIIA mRNA $(13,16)$. Nonetheless, the relative abundance of P450IIIA4 mRNA in enterocytes is consistent with our previous observations that P450IIIA catalytic activity and the concentration of P450IIIA protein was comparable in microsomes prepared from enterocytes and liver obtained from several patients (29).

We also provided evidence that enterocyte P450IIIA4 is inducible. Treatment with rifampin, a drug known to induce P450IIIA4 in liver (19-21), resulted in increases in the biopsy concentrations of P450IIIA4 mRNA in each of the healthy volunteers (Fig. 3 and 4 ). The effect of rifampin appeared to be specific because the drug had no consistent effect on the biopsy concentrations of two other enterocyte mRNAs, SI and FABP (Fig. 3). Induction in P450IIIA4 mRNA was accompanied by an increase in P450IIIA immunoreactive protein (Fig. 2) and, in the one subject studied, catalytic activity characteristic of P450IIIA4.
P450IIIA4 in enterocytes probably accounts for the significant first pass metabolism of CsA that occurs at the level of the intestine. The CsA metabolites we identified in portal blood during the anhepatic phase of the liver transplantation operation (27) are those characteristically produced by P450IIIA4 (14). In addition, P450IIIA related proteins were only detected in mature enterocytes and not in the many other cell types present in the biopsies, even after the volunteers were treated with rifampin (Fig. 2). Our immunohistochemistry results differ from those reported by Murray et al. (42) in this regard. Using a monoclonal antibody that reacted with a purified P450IIIA protein, these investigators reported strong staining of polymorphonuclear leukocytes and mast cells in addition to mature enterocytes in intestinal biopsies. It seems likely that the antibody used by these investigators, which was not as well characterized as our polyclonal antibody, was not specific for P450IIIA proteins.

There appeared to be differences between the patients in the enterocyte content of P450IIIA4 mRNA before they received rifampin (Fig. 3). These patients had received no medications for at least $1 \mathrm{wk}$ and had fasted overnight. The situation in intestine may be similar to that in liver where there are signifcant interindividual differences in P450IIIA4 expression that cannot be currently attributed to environmental factors alone (18). If confirmed, interindividual heterogeneity in P450IIIA4 expression in enterocytes could in part account for well known interpatient differences in oral bioavailability of CsA (43). Poor oral bioavailability is characteristic of P450IIIA4 substrates other than CsA (18), and based on our observations, it seems likely that enterocyte metabolism accounts in part for this property.

The identification of inducible P450IIIA4 in enterocytes also supports the idea that some important drug interactions thought to occur exclusively in liver may also occur at the level of the intestine. Indeed, some observations can now be interpreted as indicating that the intestine may be the major site for interactions involving P450IIIA4. For example, erythromycin inhibition of P450IIIA4 in either liver or intestine could account for the increased bioavailability of CsA observed in patients taking erythromycin. However, it has been reported that orally administered erythromycin has little effect on the rate of systemic clearance of CsA (23), a kinetic parameter that should mainly reflect liver P450IIIA4 activity. This observation suggests that inhibition of P450IIIA4 in intestine is the major mechanism behind the interaction between CsA and orally administered erythromycin.

The well known interaction between rifampin and CsA could also be explained by induction of P450IIIA4 in either liver or intestine. A significant contribution of the intestine to this interaction is supported by our report (44) of a liver transplant recipient who had low P450IIIA4 catalytic activity as measured by the erythromycin breath test (19). Normalization of this patient's liver P450IIIA4 with rifampin treatment virtually abolished the oral bioavailability of cyclosporine A. Induction of enterocyte P450IIIA4 now provides a likely explanation for these observations. It remains to be determined whether other drugs that are believed to cause interactions with CsA by inducing hepatic P450IIIA, such as antiseizure drugs (20), also induce P450IIIA4 in the enterocyte.

A central role of enterocyte P450IIIA4 in drug interactions is also supported by our recent studies in an in vivo rat model (28). A P450IIIA enzyme (P450IIIA1) is inducible in both 
hepatocytes and enterocytes in the rat (45). Intestinal first pass metabolism was reduced in rats pretreated with oral erythromycin and was significantly increased in rats pretreated with an inducer of P450IIIA1 (28).

The response of human enterocytes to rifampin appeared to be rapid; an increase in P450IIIA4 mRNA was evident after just $24 \mathrm{~h}$ of treatment and P450IIIA4 mRNA concentration had returned to roughly baseline levels just $3 \mathrm{~d}$ after the last rifampin dose (Fig. 5). If enterocyte P450IIIA4 mRNA correlates with catalytic activity, our observations suggest that drug interactions involving induction of enterocyte P450IIIA4 should occur within $24 \mathrm{~h}$ of exposure to the inducer, and should be largely gone within $3 \mathrm{~d}$ of removal of the inducer.

It should be pointed out that it is not possible to exclude the presence or induction of P450IIIA3 in enterocytes based on our data. We were able to use oligonucleotide probes on Northern blots to confidently identify P450IIIA4 mRNA in enterocytes because P450IIIA4 cDNA contains a 20-bp insert relative to P450IIIA3 cDNA $(13,16,39)$. However, it was not possible to design an oligonucleotide probe that would hybridize to P450IIIA3 mRNA, but not hybridize to P450IIIA4 mRNA. It seems unlikely that P450IIIA3 mRNA, if present, would be as abundant in enterocytes as P450IIIA4 mRNA. This is because we have found that when Northern blots of multiple samples of enterocyte RNA (such as that shown in Fig. 1) are hybridized with a P450IIIA cDNA under low stringency conditions, the resulting autoradiogram is virtually indistinguishable from that resulting from hybridization with the P450IIIA4-specific probe under stringent conditions (unpublished observations). Unless P450IIIA3 and P450IIIA4 mRNAs are coordinately regulated in enterocytes, these observations support the hypothesis that P450IIIA4 mRNA is the major P450IIIA mRNA expressed in human enterocytes. Since P450IIIA enzymes appear to account for $\sim 70 \%$ of the total P450 present in human enterocytes (29), it seems likely that P450IIIA4 is the major single P450 present in these cells.

In summary, our data indicate that rifampin-inducible P450IIIA4 is the predominant P450IIIA enzyme expressed in human enterocytes. Significant first pass metabolism of P450IIIA substrates has been shown to occur in the intestine; identification of P450IIIA4 in enterocytes appears to partially account for the poor oral bioavailability and drug interactions characteristic of P450IIIA4 substrates. Because recombinant expressed P450IIIA4 is now commercially available (Gentest Corp., Woburn, MA), it is relatively simple to determine whether a given compound is a substrate for this enzyme. This information may predict oral bioavailability and drug interactions of a compound, information that could be very useful in drug development. Moreover, since enterocyte P450IIIA4 is selectively inhibitable or inducible, it should now be possible to up or down regulate the enterocyte enzyme and thereby control entry into the body of a major group of xenobiotics.

\section{Acknowledgments}

We are grateful to William O. Dobbins III, M.D., for his interpretation of the immunohistochemistry sections.

This research was supported by the National Institutes of Health (GM-38149 and ES-04238 to Dr. Watkins, and 5-MO1-00042 to The General Clinical Research Center Program, University of Michigan). Dr. Kolars is the recipient of an Associate Investigator Career Development Award from The Veterans Administration.

\section{References}

1. Watkins, P. B., S. A. Wrighton, P. Maurel, E. G. Schuetz, G. Mendez-Picon, G. A. Parker, and P. S. Guzelian. 1985. Identification of an inducible form of cytochrome P-450 in human liver. Proc. Natl. Acad. Sci. USA. 82:6310-6314.

2. Shimada, T., and F. P. Guengerich. 1989. Evidence for cytochrome $\mathrm{P}-450 \mathrm{NF}$, the nifedipine oxidase, being the principal enzyme involved in the bioactivation of aflatoxins in human liver. Proc. Natl. Acad. Sci. USA. 86:462465.

3. Kronbach, T., V. Fischer, and U. A. Meyer. 1988. Cyclosporine metabolism in human liver: identification of a cytochrome P-450III gene family as the major cyclosporine-metabolizing enzyme explains interactions of cyclosporine with other drugs. Clin. Pharmacol. Ther. 43:630-635.

4. Combalbert, J., I. Fabre, G. Fabre, I. Dalet, J. Derancourt, J. P. Cano, and P. Maurel. 1989. Metabolism of cyclosporin A: IV. Purification and identification of the rifampicin-inducible human liver cytochrome P-450 (cyclosporin A oxidase) as a product of P450IIIA gene subfamily. Drug Metab. Dispos. 17:197207.

5. Gonzalez, F. J., B. J. Schmid, M. Umeno, O. W. McBride, J. P. Hardwick, U. A. Meyer, H. V. Gelboin, and J. R. Idle. 1988. Human P450PCNI: sequence, chromosome localization, and evidence through cDNA expression that P450PCN1 is nifedipine oxidase. DNA (NY). 7:79-86.

6. Guengerich, F. P., M. V. Martin, P. H. Beaune, P. Kremers, T. Wolff, and D. J. Waxman. 1986. Characterization of rat and human liver microsomal cytochrome $\mathrm{P}-\mathbf{4 5 0}$ forms involved in nifedipine oxidation, a prototype for genetic polymorphism in oxidative drug metabolism. J. Biol. Chem. 261:5051-5060.

7. Bargetzi, M. J., T. Aoyama, F. J. Gonzalez, and U. A. Meyer. 1989. Lidocaine metabolism in human liver microsomes by cytochrome P450IIIA4. Clin. Pharmacol. Ther. 46:521-527.

8. Guengerich, F. P., D. Meuller-Enoch, and I. A. Blair. 1986. Oxidation of quinidine by human liver cytochrome P-450. Mol. Pharmacol. 30:287-295.

9. Kronbach, T., D. Mathys, M. Umeno, F. J. Gonzalez, and U. A. Meyer. 1989. Oxidation of midazolam and triazolam by human liver cytochrome P450IIIA4. Mol. Pharmacol. 36:89-96.

10. Regina, R. W., P. H. Kari, A. Y. H. Lu, P. E. Thomas, F. P. Guengerich, and K. P. Vyas. 1991. Biotransformation of Lovastatin. Arch. Biochem. Biophys. 290:355-361.

11. Jacolot, F., I. Simon, Y. Dreano, P. Beaune, C. Riche, and F. Berthou. 1991. Identification of the cytochrome P450IIIA family as the enzymes involved in the N-demethylation of tamoxifen in human liver microsomes. Biochem. Pharmacol. 41:1911-1919.

12. Nebert, D. W., D. R. Nelson, M. J. Coon, R. W. Estabrook, R. Feyereisen, Y. Fujii-Kuriyama, F. J. Gonzalez, F. P. Guengerich, I. C. Gunsalus, E. F. Johnson, et al. 1991. The P450 superfamily: Update on new sequences, gene mapping, and recommended nomenclature. DNA Cell Biol. 10:1-14.

13. Molowa, D. T., E. G. Schuetz, S. A. Wrighton, P. B. Watkins, P. Kremers, G. Mendez-Picon, G. A. Parker, and P. S. Guzelian. 1986. Complete cDNA sequence of a cytochrome P-450 inducible by glucocorticoids in human liver. Proc. Natl. Acad. Sci. USA. 83:5311-5315.

14. Aoyama, T., S. Yamano, D. J. Waxman, D. P. Lapenson, U. A. Meyer, V. Fischer, R. Tyndale, T. Inaba, W. Kalow, H. V. Gelboin, F. J. Gonzalez. 1989. Cytochrome P-450 hPCN3, a novel cytochrome P-450IIIA gene product that is differentially expressed in adult human liver. cDNA and deduced amino acid sequence and distinct specificities of $\mathrm{CDNA}$-expressed hPCN1 and hPCN3 for the metabolism of steroid hormones and cyclosporine. J. Biol. Chem. 264:1038810395.

15. Wrighton, S. A., W. R. Brian, M. A. Sari, M. Iwasaki, F. P. Guengerich, J. L. Raucy, D. T. Molowa, and M. Vandenbranden. 1990. Studies on the expression and metabolic capabilities of human liver cytochrome P450IIIA5 (HLp3). Mol. Pharmacol. 38:207-213.

16. Bork, R. W., T. Muto, P. H. Beaune, P. K. Srivastava, R. S. Lloyd, and F. P. Guengerich. 1989. Characterization of mRNA species related to human liver cytochrome $P-450$ nifedipine oxidase and the regulation of catalytic activity. J. Biol. Chem. 264:910-919.

17. Guengerich, F. P. 1989. Characterization of human microsomal cytochrome P-450 enzymes. Annu. Rev. Pharmacol. Toxicol. 29:241-264.

18. Watkins, P. B. 1990. Role of cytochromes P450 in drug metabolism and hepatotoxicity. Semin. Liver Dis. 10:235-250.

19. Watkins, P. B., S. A. Murray, L. G. Winkelman, D. M. Heuman, S. A. Wrighton, and P. S. Guzelian. 1989. Erythromycin breath test as an assay of glucocorticoid-inducible liver cytochromes P-450. J. Clin. Invest. 83:688-697.

20. Pichard, P., I. Fabre, G. Fabre, J. Domergue, B. Saint Aubert, G. Mourad, and P. Maurel. 1990. Cyclosporin A drug interactions: screening for inducers and inhibitors of cytochrome P450 (Cyclosporin A Oxidase) in primary cultures of human hepatocytes. Drug Metab. Dispos. 18:595-606.

21. Ged, C., J. M. Rouillon, L. Pichard, J. Combalbert, N. Bressot, P. Bories, H. Michel, P. Beaune, and P. Maurel. 1989. The increase in urinary excretion of $6 \beta$-hydroxycortisol as a marker of human hepatic cytochrome P450IIIA induction. Br. J. Clin. Pharmacol. 28:373-387. 
22. Wrighton, S. A., B. J. Ring, P. B. Watkins, and M. Vandenbranden. 1989. Identification of a polymorphically expressed member of the human cytochrome P-450III family. Mol. Pharmacol. 36:97-105.

23. Gupta, S. K., A. Bakran, R. W. Johnson, and M. Rowland. 1989. Cyclosporin-erythromycin interaction in renal transplant patients. Br. J. Clin. Pharmacol. $27: 475-481$.

24. First, M. R., T. J. Schroeder, P. Weiskittel, S. A. Myre, J. W. Alexander, and A. J. Pesce. 1989. Combinant administration of cyclosporin and ketoconazole in renal transplant recipients. Lancet. ii:1198-1201.

25. Daniels, N. J., J. S. Dover, and R. K. Schachter. 1984. Interaction between cyclosporin and rifampicin. Lancet. ii:639.

26. Watkins, P. B., T. A. Hamilton, T. M. Annesley, C. N. Ellis, J. C. Kolars, and J. J. Voorhees. 1990. The erythromycin breath test as a predictor of cyclosporine A blood levels. Clin. Pharmacol. \& Ther. 48:120-129.

27. Kolars, J. C., W. M. Awni, R. M. Merion, and P. B. Watkins. 1991. First-pass metabolism of cyclosporin by the gut. Lancet. 338:1488-1490.

28. Kolars, J. C., P. L. Stetson, B. D. Rush, M. J. Ruwart, P. Schmiedlin-Ren, E. A. Duell, J. J. Voorhees, and P. B. Watkins. 1992. Cyclosporin metabolism by P450IIIA in rat enterocytes-another determinant of oral bioavailability? Transplantation (Baltimore). 53:596-602.

29. Watkins, P. B., S. A. Wrighton, E. G. Schuetz, D. T. Molowa, and P. S. Guzelian. 1987. Identification of glucocorticoid-inducible cytochromes $P-450$ in the intestinal mucosa of rats and man. J. Clin. Invest. 80:1029-1036.

30. Chomczynski, P., and N. Sacchi. 1987. Single-step method of RNA isolation by acid guanidinium thiocyanate-phenol-chloroform extraction. Anal. Biochem. 162:156-159.

31. Traber, P. G., L. Yu, G. D. Wu, and T. A. Judge. 1992. Sucrase-isomaltase gene expression along crypt-villus axis of human small intestine is regulated at level of mRNA abundance. Am. J. Physiol. 262:G123-G130.

32. Komori, M., K. Nishio, H. Ohi, M. Kitada, and T. Kamataki. 1989. Molecular cloning and sequence analysis of cDNA containing the entire coding region for human fetal liver cytochrome P-450. J. Biochem. (Tokyo). 105:161163.

33. Sweetser, D. A., E. H. Birkenmeier, I. J. Klisak, S. Zollman, R. S. Sparkes, T. Mohandas, A. J. Lusis, and J. I. Gordon. 1987. The human and rodent intestinal fatty acid binding protein genes. J. Biol. Chem. 262:16060-16071.
34. Sanger, F., S. Nicklen, and A. R. Coulson. 1977. DNA sequencing with chain-terminating inhibitors. Proc. Natl. Acad. Sci. USA. 74:5463-5467.

35. Dahlqvist, A. 1984. Assay of intestinal disaccharidases. Scand. J. Clin. Lab. Invest. 44:169-172.

36. Nash, T. 1953. The colorimetric estimation of formaldehyde by means of the Hantzsch reaction. Biochem. J. 55:416-421.

37. Wrighton, S. A., P. Maurel, E. G. Schuetz, P. B. Watkins, B. Young, and P. S. Guzelian. 1985. Identification of the cytochrome P-450 induced by macrolide antibiotics in rat liver as the glucocorticoid responsive cytochrome P-450p. Biochemistry. 24:2171-2178.

38. Poland, A. P., and D. W. Nebert. 1973. A sensitive radiometric assay of aminopyrine N-demethylation. J. Pharmacol. Exp. Ther. 184:269-277.

39. Beaune, P. H., D. R. Umbenhauer, R. W. Bork, R. S. Lloyd, and F. P. Guengerich. 1986. Isolation and sequence determination of a cDNA clone related to human cytochrome P-450 nifedipine oxidase. Proc. Natl. Acad. Sci. USA. 83:8064-8068.

40. Schuetz, J. D., D. T. Molowa, and P. S. Guzelian. 1989. Characterization of a cDNA encoding a new member of the glucocorticoid-responsive cytochromes P450 in human liver. Arch. Biochem. Biophys. 274:355-365.

41. Komori, M., K. Nishio, M. Kitada, K. Shiramatsu, K. Muroya, M. Soma, K. Nagashima, and T. Kamataki. 1990. Fetus-specific expression of a form of cytochrome P-450 in human livers. Biochemistry. 29:4430-4433.

42. Murray, G. I., T. S. Barnes, H. F. Sewell, S. W. Ewen, W. T. Melvin, and M. D. Burke. 1988. The immunocytochemical localisation and distribution of cytochrome P-450 in normal human hepatic and extrahepatic tissues with a monoclonal antibody to human cytochrome P-450. Br. J. Clin. Pharmacol. 25:465-475.

43. Ptachcinski, R. J., R. Venkatatramanan, and G. J. Burckhart. 1986. Clinical pharmacokinetics of cyclosporin. Clin. Pharmacokinet. 11:107-132.

44. Lucey, M. R., J. C. Kolars, R. M. Merion, D. A. Campbell, M. Aldrich, and P. B. Watkins. 1990. Cyclosporin toxicity at therapeutic blood levels and cytochrome P-450IIIA, Lancet. 335:11-15.

45. Kolars, J. C., P. Schmiedlin-Ren, J. Schuetz, W. O. Dobbins, S. A Wrighton, and P. B. Watkins. 1992. Heterogeneity of cytochrome P-450 III expression in rat gut epithelia. Gastroenterology. 102:1186-1198. 